\title{
AMINOPHYLLINE VERSUS ACETAMINOPHEN IN THE TREATMENT OF POST-DURAL PUNCTURE HEADACHE
}

\author{
Ahmed A. Fawaz, HanaaA. El-Gendy, Ashraf N. Saleh, Mahmoud E. Fath-Allah
}

\author{
Department of Anaesthesiology, \\ Intensive Care and Pain \\ Management Faculty of Medicine \\ Ain Shams University, Cairo, \\ Egypt. \\ Corresponding author \\ Mahmoud E. Fath-Allah \\ Mobile: (+20) 01063356000 \\ E.mail:: \\ MahmoudEssamFathAllah@gmai \\ 1.com \\ Received: 28/10/2020
}

Accepted: 1/12/2020

Online ISSN: 2735-3540

\begin{abstract}
:
Background: Post-dural puncture headache (PDPH) is one of the most common complications of lumbar punctures performed for spinal anaesthesia, neurologic investigation or inadvertent Dural puncture during Epidural anaesthesia. Despite acceptance of the postulated cause of CSF leakage and intracranial hypotension, the exact mechanism of developing PDPH is not clear. Many pharmacological options have been advocated as a therapy for PDPH with a varying degree of success, but problem in choosing main drug therapy is the lack of large randomized controlled trials proving efficacy and safety.
\end{abstract}

Aim of the Work: To compare the efficacy of aminophylline compared to acetaminophen in management of PDPH.

Patients and Methods: The current clinical trial included 70 patients aged between 18-40 years old, class I-II according to the American society of anaesthesiology having a headache that developed after Dural puncture for various surgical procedures under regional anaesthesia. Patients were randomly allocated into 2 groups (35 patients each). Patients in the study Group (A) received $250 \mathrm{mg}$ Aminophylline IV infusion while patients in Group (B) received Igm paracetamol IV infusion for management of PDPH. Baseline VAS scores were recorded before drug administration \&at 2 hours, 6 hours and 12 hours after the treatment administration.

Results: Mean VAS scores for PDPH intensity were statistically significant lower in Group A compared to Group B at 2 hours, 6 hours \& 12 hours, while baseline VAS Score for PDPH intensity was insignificant statistically between Both Groups. There was also statistically significant improvement in Group A compared to Group B according to the Patient Global impression of change (PGIC) between both groups.

Conclusion: IV injection of aminophylline is relatively straightforward and non-invasive, safe and effective treatment for PDPH, and has improved early-stage effectiveness.

Key words: aminophylline, acetaminophen, treatment, postdural puncture headache

\section{INTRODUCTION:}

Spinal anaesthesia is a simple, cost effective and efficient technique that provides complete sensory and motor block, as well as postoperative analgesia with a high success rate ${ }^{(1)}$.

Post-dural puncture headache (PDPH) is among the most common complications of lumbar punctures performed for spinal anaesthesia or neurologic investigation, with incidence rates of $8 \%$ to $37 \%$ reported in different studies ${ }^{(2)}$.

It typically begins within 2 days but may be delayed for as long as 2 weeks and almost resolves spontaneously within a few $\operatorname{days}^{(3)}$. 
The classic symptoms of (PDPH) consist of photophobia, nausea and vomiting, neck stiffness, tinnitus, diplopia, and dizziness, in addition to the often severe cephalgia. The headache is usually severe and throbbing, frontal in origin, with radiation to occiput and is exacerbated by sitting or standing. The positional nature of the headache and dramatic improvement on assuming the supine position remains the standard diagnostic criterion for this condition $^{(4)}$.

Preventive strategies of PDPH are developed based on how to reduce CSF leakage by available methods including small size pencil point spinal needle, parallel bevel orientation, and liquid use for the loss of resistance in epidural puncture ${ }^{(5)}$.

Commonly used treatments for PDPH include rehydration, the administration of corticotropin, caffeine, or sumatriptan, and the application of an Epidural blood patch $(\mathrm{EBP})^{(6)}$.

It seems that Methylxanthines' derivateions (e.g. caffeine and theophylline) lead to vascular contraction and can reduce the headache. On the other hand, these drugs may decrease the headache by blocking the purine receptors ${ }^{(7)}$.

Aminophylline, like theophylline and caffeine, can prevent PDPH by adenosine antagonization and vasoconstriction effect ${ }^{(8)}$.

Acetaminophen is one of the most important drugs used in the treatment of mild to moderate pain when an antiinflammatory effect is not necessary. The drug is one of the most commonly used nonnarcotic analgesic agentsfor mild to moderate pain such as headache ${ }^{(9)}$.

\section{AIM OF THE WORK:}

To verify the efficacy and the safety of Aminophylline for management of PDPH. Also to compare the efficacy of Amino- phylline and Acetaminophen for management of PDPH.

\section{PATIENTS AND METHODS:}

This study was carried out in Nasr City insurance hospital and Ain shams University hospitals as a prospective, single-blinded (patients only), randomized, parallel-group clinical trial in 2019. The study was approved by the research ethical committee at Ain Shams University \& all subjects provided written informed consent to be enrolled in the study after the procedure, aim and all safety measures were explained to them.

70 patients were included in this clinical trial, the inclusion criteria were patient's ages between 18 - 40 year old, class I - II according to the American society of anaesthesiologists, having a headache that developed after Dural puncture for various surgical procedures under regional anaesthesia (spinal anaesthesia, epidural anaesthesia or combined spinal and epidural anaesthesia).

PDPH was defined according to the international classification of headache disorders, 3rd edition criteria (ICHD-3) as headache occurring within 5 days of a lumber puncture, caused by CSF leakage through the dural puncture.

The diagnostic criteria according to ICHD-3 were: Either Low CSF pressure or Evidence of CSF leakage on imaging or both, Dural puncture has been performed, Headache has developed within 5 days of the dural puncture \& not better accounted for any other cause of headache according to ICHD-3 diagnosis.

The exclusion criteria included having a history of headache that could interfere with the PDPH diagnosis, having a history of central nervous system diseases, including intracranial haemorrhage, seizures, intracranial hypertension, or hydrocephalus; having a history of cardiovascular diseases, including coronary heart disease, arrhythmias, or hypertension. The patients with 
any history of allergy to or any contraindication for using Aminophylline, theophylline or Acetaminophen were excluded.

Patients were randomly recruited using computer generated program into 2 groups (35 patients each). Patients in the study Group (A) received Aminophylline (250mg of Aminophylline dissolved in $100 \mathrm{ml}$ normal saline for intravenous infusion over 30 minutes) while patients in control Group (B) received paracetamol (1gm of acetaminophen in $100 \mathrm{ml}$ for intravenous infusion over 30 minutes). All the patients in the 2 groups were blinded to the group of randomization.

Headache intensity was assessed using Visual Analogue score (VAS) bedside card.VAS scores were recorded with the patients assuming standing position. Patient lies flat for more than 10 minutes and then stands for 5 minutes and then VAS scores were recorded.

Baseline VAS scores were recorded before drug administration. VAS scores were recorded again at 2 hours, 6 hours and 12 hours after the treatment administration.

The primary end point was the headache severity after $8-12$ hours after treatment
The secondary outcomes were the overall response to treatment measured on the Patient Global impression of change (PGIC) which is a self-evaluation of the patient overall change since the start of the study.

Patients not responding to either treatment were planned to be managed invasively using Epidural Blood Patching or Epidural Saline injection.

\section{Statistical analysis:}

Recorded data were analysed using the statistical package for social sciences, version 20.0 (SPSS Inc., Chicago, Illinois, USA). Quantitative data were expressed as mean \pm standard deviation (SD). Qualitative data were expressed as frequency and percentage. The following tests were done: Independentsamples t-test of significance was used when comparing between two means. Mann Whitney z-test: for two-group comparisons in non-parametric data. Chi-square (x2) test of significance was used in order to compare proportions between qualitative parameters. The confidence interval was set to $95 \%$ and the margin of error accepted was set to $5 \%$. So, the p-value was considered significant as the following: Probability (P-value): P-value $<0.05$ was considered significant.

\section{RESULTS:}

Table (1): Demographic data

\begin{tabular}{|c|c|c|c|c|}
\hline Demographic data & $\begin{array}{c}\text { Group A } \\
(\mathrm{n}=35)\end{array}$ & $\begin{array}{c}\text { Group B } \\
(\mathrm{n}=35)\end{array}$ & $\mathrm{t} / \mathrm{x} 2 \#$ & p-value \\
\hline \multicolumn{5}{|l|}{ Age (years) } \\
\hline Range & $18-40$ & $18-40$ & \multirow[t]{2}{*}{0.851} & \multirow[t]{2}{*}{0.619} \\
\hline Mean \pm SD & $32.77 \pm 8.85$ & $31.79 \pm 8.58$ & & \\
\hline \multicolumn{5}{|l|}{ Sex } \\
\hline Male & $22(62.9 \%)$ & $25(71.4 \%)$ & \multirow[t]{2}{*}{$2.194 \#$} & \multirow[t]{2}{*}{0.396} \\
\hline Female & $13(37.1 \%)$ & $10(28.6 \%)$ & & \\
\hline Weight $(\mathrm{kg})$ & $72.76 \pm 5.56$ & $75.11 \pm 9.31$ & 1.049 & 0.220 \\
\hline \multicolumn{5}{|l|}{ ASA } \\
\hline I & $19(54.3 \%)$ & $22(62.9 \%)$ & \multirow[t]{2}{*}{1.386} & \multirow[t]{2}{*}{0.291} \\
\hline II & $16(45.7 \%)$ & $13(37.1 \%)$ & & \\
\hline Duration of surgery (min) & $96.30 \pm 24.61$ & $99.51 \pm 20.33$ & 1.154 & 0.242 \\
\hline Duration of hospital stay (days) & $2.25 \pm 0.86$ & $2.02 \pm 0.75$ & 1.269 & 0.267 \\
\hline
\end{tabular}

As table (1) shows, there was no the two groups according to demographic statistically significant difference between data included: Age, Sex, Weight, American 
Society of anaesthesiologists' classification (ASA), Duration of surgery \& Duration of hospital stay.

Baseline VAS scores were recorded before drug administration. VAS scores Table (2): Comparison between group A and group B according to headache intensity.

\begin{tabular}{|l|c|c|c|c|}
\hline Headache intensity & $\begin{array}{c}\text { Group A } \\
(\mathrm{n}=35)\end{array}$ & $\begin{array}{c}\text { Group B } \\
(\mathrm{n}=35)\end{array}$ & z-test & p-value \\
\hline Baseline & $6.17 \pm 1.37$ & $6.73 \pm 1.24$ & 1.713 & 0.207 \\
\hline After 2 hrs & $5.65 \pm 1.62$ & $6.75 \pm 1.31$ & 2.592 & $0.019^{*}$ \\
\hline After 6 hrs & $3.88 \pm 1.78$ & $4.89 \pm 1.53$ & 3.576 & $0.008^{*}$ \\
\hline After 12 hrs & $2.75 \pm 2.42$ & $4.79 \pm 2.03$ & 4.196 & $<0.001^{* *}$ \\
\hline
\end{tabular}

In Group A the mean baseline VAS Score for PDPH intensity was $6.17 \pm 1.37$. While the mean VAS scores for PDPH intensity 2 hours, 6 hours \& 12 hours after Aminophylline administration were $5.65 \pm 1.62, \quad 3.88 \pm 1.78 \quad \& \quad 2.75 \pm 2.42$ respectively.

In Group B the mean baseline VAS Score for PDPH intensity was 6.73 \pm 1.24 . While the mean VAS scores for PDPH intensity 2 hours, 6 hours \& 12 hours after Acetaminophen administration were $6.75 \pm$ $1.31,4.89 \pm 1.53 \& 4.79 \pm 2.03$ respectively.

Mean VAS scores for PDPH intensity were statistically significant lower in Group were recorded again at 2 hours, 6 hours and 12 hours after the treatment administration in both studied groups.
A compared to Group B at 2 hours, 6 hours \& 12 hours, while baseline VAS Score for PDPH intensity was insignificant statistically between Both Groups as shown in table (2).

On the Patient Global impression of change (PGIC), 26 patients in Group A reported that their pain symptoms were much improved or very much improved, while 18 patients in Group B reported the same.

Also only 8 patients in Group A stated that there was no change in their pain stated the same. symptoms while 14 patients in Group B

Table (3): Comparison between group A and group B according to PGIC

\begin{tabular}{|l|c|c|c|c|}
\hline PGIC & $\begin{array}{c}\text { Group A } \\
(\mathbf{n = 3 5})\end{array}$ & $\begin{array}{c}\text { Group B } \\
(\mathbf{n = 3 5})\end{array}$ & $\mathbf{x 2}$ & p-value \\
\hline Improved & $26(74.2 \%)$ & $18(51.4 \%)$ & 10.171 & $<0.001 * *$ \\
\hline No change & $8(22.9 \%)$ & $14(40 \%)$ & 6.012 & $0.014^{*}$ \\
\hline Worse & $1(2.9 \%)$ & $3(8.6 \%)$ & 2.038 & 0.153 \\
\hline
\end{tabular}

x2: Chi-square test, p-value $>0.05 \mathrm{NS} ;{ }^{*}$-value $<0.05 \mathrm{~S} ; * *$ p-value $<0.001 \mathrm{HS}$

There was statistically significant improvement in Group A compared to Group B according to PGIC (improved \& no change) as shown in table (3) \& diagram. (1). 
Diagram (1):

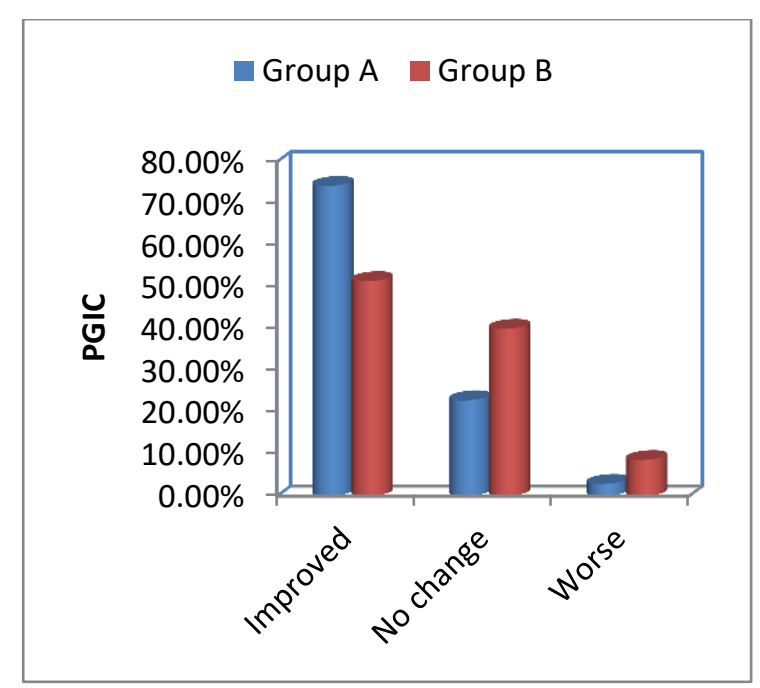

Bar chart between group A and group B according to PGIC.

\section{DISCUSSION:}

Lumbar puncture (LP) is a routine technique performed for a variety of procedures, for example diagnosis, administration of drugs, myelography, and spinal anaesthesia. PDPH is a common complication $(30-40 \%)$ of diagnostic $\mathrm{LP}^{(10)}$.

However, the exact mechanism of PDPH remains unclear and might be related to the following factors: decreased intracranial pressure leading to the compensatory expansion of the intracranial blood vessels and increased blood flow, resulting in $\mathrm{PDPH}^{(11)}$.

Moreover, As a result of CSF leakage and CSF volume depletion, the brain descends. This leads to traction or distortion of various anchoring pain-sensitive structures in the brain, causing orthostatic or primarily orthostatic headaches ${ }^{(12)}$.

Methylxanthines are beneficial in controlling the compensatory vasodilatation associated with PDPH. Methylxanthines are thought to interfere with the uptake of calcium by the sarcoplasmic reticulum, block activity of phosphodiesterase and antagonize the effects of adenosine. The cerebral vasoconstriction is most likely due to the antagonizing effect of adenosine. In addition, methylxanthines increase CSF production by stimulating sodium-potassium pumps $^{(13)}$.

Caffeine and acetaminophen is the most widely accepted pharmacologic treatment for PDPH; it has proven to be effective in decreasing the proportion of participants with PDPH persistence and those requiring supplementary interventions. Traditional therapies such as bed rest and rehydration are usually ineffective when the headache is severe $^{(14)}$.

The dose of aminophylline used in this study was lower than that used for regular clinical treatments and would, hence, not have caused an excessive plasma concentration, explaining the absence of adverse reactions related to the drug treatment. Therefore, the study results show that an IV injection of $250 \mathrm{mg}$ aminophylline can be regarded a safe treatment for PDPH.

Our results showed that administration of aminophylline $250 \mathrm{mg}$ produced a great reduction in VAS score for PDPH compared with $1 \mathrm{gm}$ of acetaminophen despite baseline VAS Score for PDPH intensity was 
insignificant statistically between Both Groups.

In agreement with our study Camann et al. (1990) evaluated the possibility of oral caffeine for the treatment of PDPHs. The study was randomized, double-blind, and placebo-controlled involving 40 postpartum patients. Each patient was randomized to receive caffeine capsules $300 \mathrm{mg}$ po or placebo. A $100-\mathrm{mm}$ visual analog scale was used to evaluate the pain for the headache at baseline, 4 hours, and 24 hours after caffeine administration. They concluded that caffeine administered orally provides relief, albeit if sometimes transient, from PDPH with minimal side effects ${ }^{(14)}$.

In addition, Ergün et al. (2008) evaluated the efficacy of intravenous theophylline treatment for PDPH in comparison with a placebo in randomized, double blinded study. 33 patients with PDPH were randomly allocated into 2 groups : study group (17 patient ) received $200 \mathrm{mg}$ intravenous theophylline (200 mg theophylline in $100 \mathrm{~mL} 5 \%$ dextrose) infusion over $40 \mathrm{~min}$, and control group (16 patients) were given $100 \mathrm{~mL} 5 \%$ dextrose intravenously over $40 \mathrm{~min}$. Then the two groups were asked for their VAS values $4 \mathrm{~h}$ after the infusion while in the standing position, and then the values were compared. They found that intravenous theophylline infusion was effective for decreasing the painfulness of PDPH compared with the control group ${ }^{(6)}$.

In addition, Mahoori et al. (2013) compared the efficacy of oral theophylline to oral acetaminophen. In a single-blind randomized clinical trial, 60 patients with Class I physical status according to ASA classification system, who suffered from PDPH were enrolled. Patients in Theophylline group were received theophylline tablet $250 \mathrm{mg}$ three times per day, and in the other group acetaminophen $500 \mathrm{mg}$ three times per day was administered. The main VAS values were significantly lower in theophylline group in comparison with the acetaminophen with No adverse effects reported $^{(15)}$.

In addition, Sen \& Sen (2013) studied the efficacy of oral Theophylline for the management of PDPH in comparison to conservative management. Forty patients with PDPH, whose surgeries were done under spinal anaesthesia, were selected randomly and divided into two groups of 20 each. One group received conservative treatment and the other group Theophylline $(400 \mathrm{mg}$ ) only orally. Intensity of headache was analyzed using a VAS of pain. Assessment was done immediately before ( 0 h) and at 8, 16 and 24th hr of drug administration. Significantly better relief of PDPH was found in Theophylline group than the conservative group Recurrence of headache was found much less in the Theophylline group compared to the other $\operatorname{group}^{(16)}$.

In addition Chuanjie et al. (2016) studied the efficacy and safety of an intravenous injection of aminophylline in management of PDPH. Thirty-two PDPH patients received Aminophylline $(250 \mathrm{mg}$ ) was dissolved in $100 \mathrm{~mL}$ saline for IV injection and was administered over at least 30 minutes, once daily for 2 consecutive days. The primary and secondary endpoints were the degree of headache and the patient's overall response to the treatment, respectively. VAS scores were determined with the patient's standing position (lies flat for more than 10 minutes and then stands for 5 minutes) before the first aminophylline treatment and at 30 minutes, one hour, 8 hours, one day, and 2 days after treatment. Treatment safety was evaluated based on the occurrence of adverse reactions. They found that Aminophylline significantly reduced the VAS scores for Headache with More than $50 \%(17 / 32)$ of the patients reported that they were "very much improved" or "much improved" 30 minutes after the initial 
treatment, increasing to $93.8 \%(30 / 32)$ at 2 days post-treatment ${ }^{(17)}$.

In addition Chuanjie et al. (2018) studied the efficacy and safety of an intravenous injection of aminophylline compared with placebo in management of PDPH. 126 patients were enrolled \& randomly assigned to groups receiving either IV aminophylline or a placebo within 3 hours of symptom onset once daily for 2 consecutive days. The primary endpoint was headache severity 8 hours after treatment. The aminophylline group received $250 \mathrm{mg}$ aminophylline dissolved in $100 \mathrm{~mL}$ saline for IV injection over $\geq 30$ minutes once daily for 2 consecutive days. The placebo group received isochoric, $100 \mathrm{~mL}$ isotonic saline injections on the same schedule. They found that Compared to the placebo-treated patients, the aminophylline-treated patients had significantly lower mean VAS scores 8 hours after treatment and were significantly more likely to report improvements on the PGIC. This therapeutic effect was already evident at the 30-minute time point and persisted for 2 days. There was no significant difference in the incidence of adverse events $^{(18)}$.

Also Sadeghi et al. (2012) studied whether single dose of intravenous aminophylline can be used as prophylaxis of this complication in cesarean section or not. 120 patients undergoing spinal anesthesia for the elective cesarean section participated. After cord clamping, $1 \mathrm{mg} / \mathrm{kg}$ aminophylline injected intravenously in 60 patients but others didn't receive it. At $1^{\text {st }}, 4^{\text {th }}, 24^{\text {th }}$ and $48^{\text {th }}$ hours after operation, these 120 patients evaluated for PDPH. They found that the incidence of PDPH decreases in those patients who received single dose intravenous aminophylline after cord clamping $^{(19)}$.

In addition, Chao-Jie et al. (2019) investigated the effect and safety of the preadministration with aminophylline on the occurrence of PDPH in women undergoing caesarean section by combined spinalepidural anaesthesia. 120 women undergoing elective caesarean sections with combined spinal-epidural anaesthesia were randomly allocated into two groups; for 30 min immediately after the infant was delivered, group (A) received $250 \mathrm{mg}$ aminophylline intravenously and group (B) received an equal volume of normal saline. The incidence of PDPH in group A was significantly lower than group B. There were no related side-effects within $24 \mathrm{~h}$ after aminophylline administration in group $\mathrm{A}^{(20)}$.

In addition, Naghibi \&Hamidi (2014) studied the effects of combining administration of intravenous aminophylline and dexamethasone on PDPH in patients who underwent lower extremity surgery in comparison with using either drug alone and also comparing them with placebo. 140 patients aged 20-65 years were divided into four groups of 35 each and received aminophylline $1.5 \mathrm{mg} / \mathrm{kg}$ i.v. (group A), dexamethasone $0.1 \mathrm{mg} / \mathrm{kg}$ (group D), aminophylline $\quad 1.5 \mathrm{mg} / \mathrm{kg}$ plus dexamethasone $0.1 \mathrm{mg} / \mathrm{kg}$ i.v. (group AD), and placebo (group P). The incidences of $\mathrm{PDPH}$ and complete response were evaluated at 6-48 $\mathrm{h}$ after arrival to the ward in the four groups by using VAS score. Acetaminophen $15 \mathrm{mg} / \mathrm{kg}$ i.v. was administered if the patients had VAS score of $>5 \mathrm{~cm}$ and the total dose of rescue analgesic was recorded. They concluded that Combine administration of aminophylline $1.5 \mathrm{mg} / \mathrm{kg}$ plus dexamethasone $0.1 \mathrm{mg} / \mathrm{kg}$ significantly reduced PDPH better than using either drug alone in patients who underwent lower extremity surgery. Postoperative analgesic requirement was significantly less in groups $\mathrm{A}, \mathrm{D}$, and $\mathrm{AD}$ compared with group P. The results of this study did not show any significant adverse effect such as tachycardia or restlessness due to study drug administration ${ }^{(21)}$.

In contrast to the results of our study, Laleh et al. (2019) compared the effect of 


\section{Ahmed A. Fawaz, et al.,}

ondansetron to aminophylline on the incidence and severity of PDPH in women undergoing elective caesarean section surgery. 300 women who were candidates for elective caesarean section surgery were randomly assigned to 3 groups: group (A) receiving $\quad 1 \mathrm{mg} / \mathrm{kg}$ intravenous aminophylline, or (B) receiving $0.15 \mathrm{mg} / \mathrm{kg}$ IV ondansetron or (C) control group receiving $5 \mathrm{cc}$ normal saline as placebo. Afterwards, PDPH and post-operative nausea and vomiting were followed during 24, 48 and $72 \mathrm{~h}$ periods since the performance of spinal anaesthesia and the severity of headache was noted by numerical rating scale which had been already explained to the patients. This study shows that although $(0.15 \mathrm{mg} / \mathrm{kg})$ ondansetron does not reduce the incidence of PDPH, it significantly reduces the severity of headache also shows that aminophylline has no effect on reduction of incidence nor severity of PDPH. This can be explained by low dose of Aminophylline (1 $\mathrm{mg} / \mathrm{kg})$ compared to the present study ${ }^{(22)}$.

\section{Conclusion:}

In this study, we administered an IV injection of aminophylline to treat PDPH. The treatment was relatively straightforward and non-invasive, safe and effective treatment for PDPH, and has improved early-stage effectiveness. Therefore, we believe that an IV injection of aminophylline could be the preferred method for the clinical treatment of PDPH.

\section{REFERENCES:}

1. Houtermans-Auckel JP, van Rossum E, Teijink JAW, Dahlmans AAHR, Eussen EFB, Nicolaï SPA, et al. To Wear or not to Wear Compression Stockings after Varicose Vein Stripping: A Randomised Controlled Trial. Eur J Vasc Endovasc Surg. 2009;38(3):387-91.

2. Amorim JA, Gomes De Barros M V.,
Valença MM. Post-dural (post-lumbar) puncture headache: Risk factors and clinical features. Cephalalgia. 2012;32:916-23.

3. Bradbury CL, Singh SI, Badder SR, Wakely LJ, Jones PM. Prevention of post-dural puncture headache in parturients: A systematic review and meta-analysis. Acta Anaesthesiologica Scandinavica. 2013.

4. Nepomuceno R, Herd A. Bilateral subdural hematoma after inadvertent dural puncture during epidural analgesia. J Emerg Med. 2013;

5. Xu H, Liu Y, Song W, Kan S, Liu F, Zhang $\mathrm{D}$, et al. Comparison of cutting and pencilpoint spinal needle in spinal anesthesia regarding postdural puncture headache. Medicine (United States). 2017.

6. Ergün U, Say B, Ozer G, Tunc T, Sen M, Tüfekcioglu $S$, et al. Intravenous theophylline decreases post-dural puncture headaches. J Clin Neurosci. 2008;15(10):1102-4.

7. Miller RD. Miller's Anesthesia Vol. 2. In: Miller's Anesthesia. 2005.

8. Pranjal S ST. Post-lumbar puncture headache. Hosp Physician. 2007;43:51-4.

9. Katzung BG. Basic \& Clinical Pharmacology, Fourteenth Edition. Basic and Clinical Pharmacology. 2018.

10. Schwarz U, Schwan C, Strumpf M, Witscher K, Zenz M. [Postdural puncture headache: diagnosis, prevention and therapy]. Schmerz. 1999;

11. Liu H, Kaye A, Comarda N, Li M. Paradoxical postural cerebrospinal fluid leak-induced headache: report of two cases. J Clin Anesth. 2008;8:374-7.

12. Straube A, Neudert C, Glas M, Brüning R, Padovan CS. [The so-called spontaneous low CSF pressure pressure syndrome. Case results indicating a disturbance in CSF/blood volume regulation]. Nervenarzt. 2004;

13. Choi A, Laurito CE, Cunningham FE. 
Pharmacologic management of postdural puncture headache. Ann Pharmacother. 1996;30(7-8):831-9.

14. Camann WR, Murray RS, Mushlin PS, Lambert DH. Effects of oral caffeine on postdural puncture headache. A doubleblind, placebo-controlled trial. Anesth Analg. 1990;(70):181-4.

15. Mahoori A, Hassani E, Noroozinia $H$, Javaheri N, Hatami S. Theophylline versus acetaminophen in the treatment of postdural puncture headache (PDPH). Middle East J Anesthesiol. 2013;22(3):289-92.

16. Sen J, Sen B. Non invasive management of post dural puncture headache - A comparison. Bangladesh J Med Sci. 2014;13(2):114-8.

17. Wu C, Lian Y, Guan D, Wang L, Miao Y, Xie N, et al. A multicenter clinical study on treating post-dural puncture headache with an intravenous injection of aminophylline. Pain Physician. 2016;19(5):E761-5.

18. Wu C, Guan D, Ren M, Ma Z, Wan C, Cui $\mathrm{Y}$, et al. Aminophylline for treatment of postdural puncture headache: A randomized clinical trial. Neurology. 2018;90(17): E1523-9.
19. Sadeghi SE, Abdollahifard G, Nasabi NA, Mehrabi M, Safarpour AR. Effectiveness of single dose intravenous aminophylline administration on prevention of Post Dural Puncture Headache in patients who received spinal anesthesia for elective cesarean section. World J Med Sci. 2012;7(1):13-6.

20. Yang CJ, Chen T, Ni X, Yu WY, Wang W. Effect of pre-administration with aminophylline on the occurrence of postdural puncture headache in women undergoing caesarean section by combined spinal-epidural anaesthesia. J Int Med Res. 2019;

21. Hamidi M, Naghibi K. Prophylactic administration of aminophylline plus dexamethasone reduces post-dural puncture headache better than using either drug alone in patients undergoing lower extremity surgery. Adv Biomed Res. 2014;3(1):5.

22. Dehghanpisheh L, Bayani S, Azemati S, Rakhshan M. The effect of intravenous administration of ondansetron compared to aminophylline on incidence and severity of post-dural puncture headache (PDPH) in cesarean section surgeries. Biomed Res. 2019;30(5):1-6. 
مقارنة بين عقار الأمينوفيللين وعقار الأسيتامينوفين في علاج صداع ما بعد ثقب الجافية

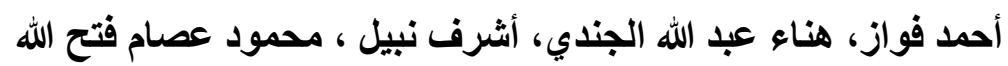

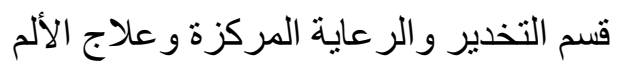

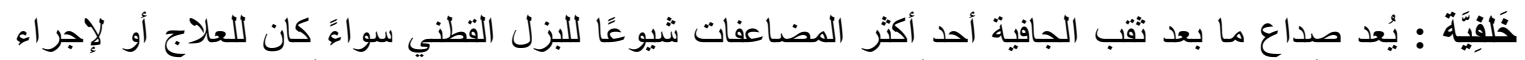

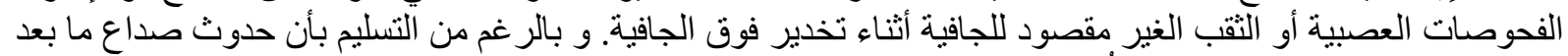

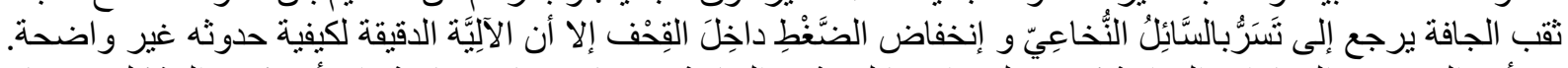

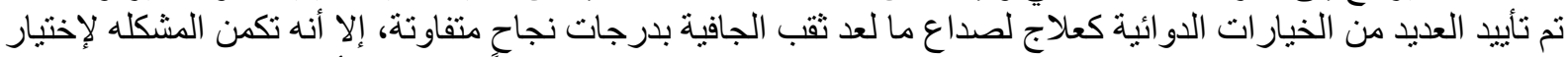

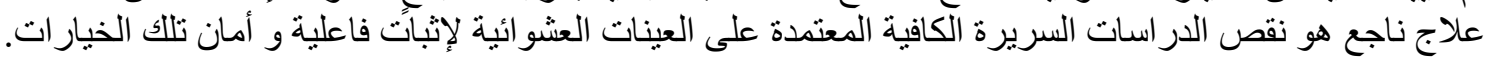

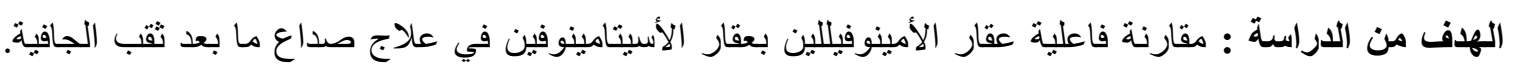

المرضى

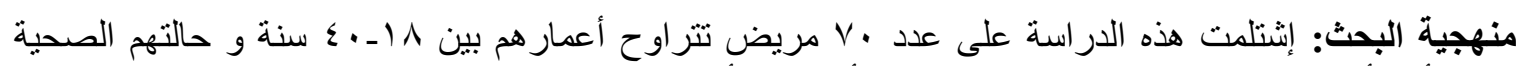

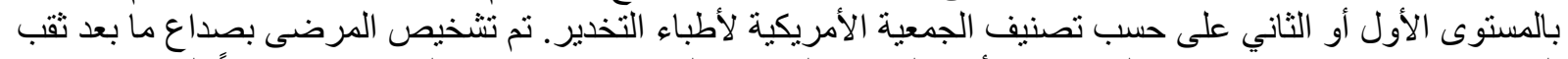

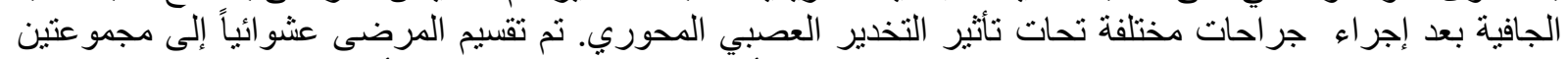

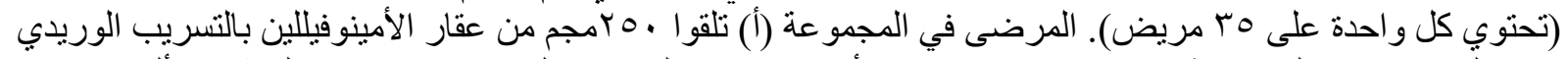

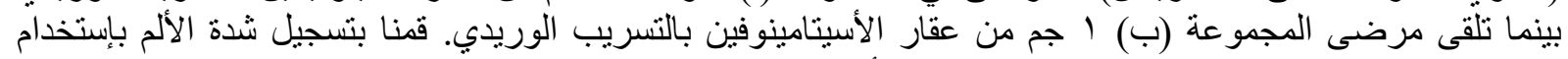

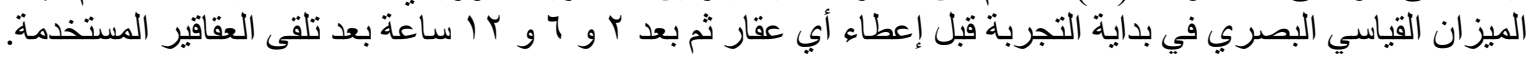

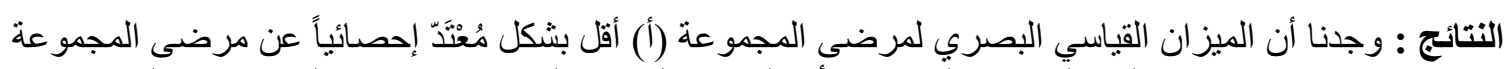

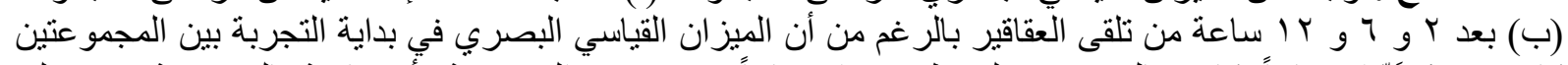

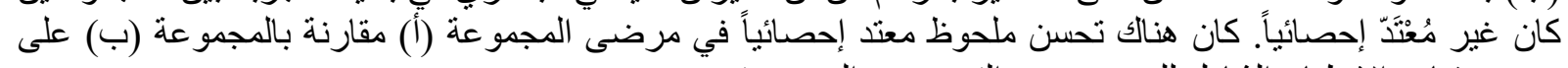

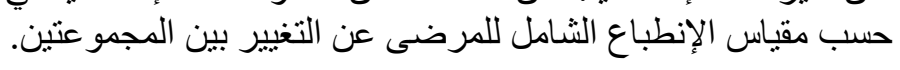

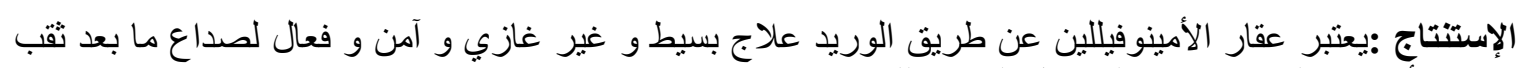

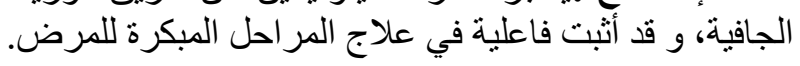

